\title{
CLINICAL COURSE OF ERYTHEMA NODOSUM LEPROSUM: AN 11-YEAR COHORT STUDY IN HYDERABAD, INDIA
}

\author{
LEONOR POCATERRA, SUMAN JAIN, RAJGOPAL REDDY, SYED MUZAFFARULLAH, OBDULITA TORRES, \\ SUJAI SUNEETHA, AND DIANA N. J. LOCKWOOD* \\ Clinical Research Unit, London School of Hygiene and Tropical Medicine, London, United Kingdom; Blue Peter Research Centre, \\ Cherlapally, Hyderabad, India; Cátedra de Parasitología, Escuela de Medicina JM Vargas, Universidad Central de Venezuela, \\ Caracas, Venezuela
}

\begin{abstract}
Erythema nodosum leprosum (ENL) or type 2 lepra reactions complicate lepromatous leprosy and borderline lepromatous leprosy. We report an 11-year retrospective case record analysis of 481 outpatients with borderline lepromatous and lepromatous leprosy at the Dhoolpet Leprosy Research Center in Hyderabad, India.. The overall prevalence of ENL was $24 \%, 49.4 \%$ among cases of lepromatous leprosy (LL) and $9 \%$ among cases of borderline lepromatous (BL) leprosy. Logistic regression analysis identified LL (odds ratio $[\mathrm{OR}]=8.4,95 \%$ confidence interval $[\mathrm{CI}]=4.6-15.4, P<0.001)$ and $\mathrm{BL}$ with a bacterial index $\geq 4+(\mathrm{OR}=5.2,95 \% \mathrm{CI}=2.1-12.9, P=0.001)$ as major risk factors. The average patient with ENL was male, 34.7 years of age, and had multiple episodes of ENL $($ mean $=3.1)$ over an 18.5-month period. Three types of ENL were identified: single acute ENL, multiple acute ENL (repeated discrete episodes), and chronic ENL (continuous episodes). Acute single ENL is rare, accounting for only $8 \%$ of cases. Chronic ENL accounted for $62.5 \%$ of the cohort. Chronic ENL was of longer duration and more severe. An age $\geq 35$ years was a risk factor for developing chronic ENL. Patients with chronic ENL were more compliant with multi-drug therapy, especially during the first six doses of multi-drug therapy. Distinguishing these different types of ENL would be useful for patient management and developing improved treatment of these debilitating reactions. Improved strategies for treatment and management of these reactions need to be developed.
\end{abstract}

\section{INTRODUCTION}

Erythema nodosum leprosum (ENL) or type 2 reactions are serious, difficult to manage, immune-mediated complications of lepromatous leprosy (LL) and borderline lepromatous (BL) leprosy. Patients with ENL become acutely sick with fever, malaise, and crops of painful erythematous nodules. ${ }^{1}$ Inflammation often affects other systems causing iritis, neuritis, myositis, lymphadenitis, arthritis, dactylitis, and orchitis. The underlying pathology is of antigen-antibody immune complex deposition, ${ }^{2}$ but there is also evidence of $\mathrm{T}$ cell and macrophage dysregulation with overproduction of the cytokine tumor necrosis factor $\alpha .{ }^{3}$ Thirty years ago during the dapsone monotherapy era, the prevalence of ENL was approximately $50 \%$ and $30 \%$ among LL and BL patients respectively. ${ }^{4}$ These prevalences have decreased with the widespread implementation of multi-drug therapy for multibacillary (MB) leprosy recommended by the World Health Organization (WHO-MB-MDT) partly because of earlier diagnosis and treatment and partly because clofazimine, one of the core anti-bacterial drugs, also has an anti-inflammatory effect. ${ }^{5}$ Contemporary estimates of the frequency of ENL among lepromatous patients range from $25 \%$ of new multibacillary patients in Brazil, ${ }^{6}$ to $26 \%$ of lepromatous patient in northeastern Thailand, ${ }^{7}$ to $5 \%$ in Ethiopia. ${ }^{8}$

ENL has a relapsing and remitting course that may last for several years. Levy and others found that ENL produces greater disability than the underlying lepromatous leprosy and was the commonest reason for admission to the hospital. ${ }^{9}$ Treatment requires immunosuppression. Steroids are often used as the first-line treatment but patients may require treatment over several years. Thalidomide is highly effective in treating the acute inflammation and also in maintaining long

\footnotetext{
* Address correspondence to Diana N. J. Lockwood, Clinical Research Unit, London School of Hygiene and Tropical Medicine, Keppel Street, London WC1E 7HT, United Kingdom. E-mail: diana.lockwood@1shtm.ac.uk
}

term immunosuppression with few side effects. ${ }^{10}$ Although ENL is widely recognized to have a long time course, there are no data of the time course of ENL for individual patients. We have classified ENL into three types, acute ENL, comprising a single episode; acute recurrent ENL, comprising multiple discrete episodes; and chronic ENL, with continuous episodes. These types of ENL could have different risk factors and require different therapeutic intervention. If patients who were likely to have only single, widely spaced episodes of ENL could be identified, they could be safely treated with short courses of steroids with no risk of steroid dependency or adverse effects. Defining these different types could be important in designing therapeutic interventions and health care planning.

There is little data on risk factors for ENL. One study from Nepal of 118 patients identified LL (odds ratio [OR] $=2.88$ ) and skin infiltration $(\mathrm{OR}=2.71)$ as the most important risk factors. ${ }^{1}$ An age greater than 40 years was a protective factor $(\mathrm{OR}=0.69)$. In that study, the average number of ENL episodes per patient was two, using three months as the time interval to define a new ENL episode. ${ }^{1}$

The present study was conducted in Hyderabad, Andhra Pradesh, India from January 1990 to December 2000, an 11year period when MDT was used as standard therapy, to determine the prevalence of ENL in BL and LL patients; identify risk factors for developing ENL; describe the number of episodes and duration of ENL in this cohort; classify ENL into acute and chronic forms; and identify risk factors for the different types of ENL.

\section{MATERIALS AND METHODS}

The study was a retrospective review conducted at the Dhoolpet Leprosy Research Center/Lepra India Blue Peter Research Center (DLRC/BPRC) in Hyderabad, Andhra Pradesh, India. This is a leprosy referral center situated in Hyderabad, India. This center is funded by the United King- 
dom Medical Research Council through Lepra India. Leprosy patients are self-referred and physicians are referred. It does not have an associated leprosy control program. We examined the hospital records of all treated and untreated BL leprosy patients and LL patients registered between January 1990 and December 2000. The study was reviewed and approved by the Blue Peter Research Committee.

Data were collected from the patients' first consultation through their monthly reviews while receiving MDT to completion of antibacterial treatment from the patient record cards. These data included year of birth, sex, Ridley-Jopling classification at diagnosis, bacterial index (BI), total number of doses of MB-MDT taken, total length of time taking MBMDT, and episodes of ENL.

For patients with ENL, we also collected the date of leprosy diagnosis at the research center, year of leprosy onset, the date of starting and ending each episode of ENL, severity, number of MB-MDT doses taken, total amount of prednisolone given, highest dose of prednisolone given at each ENL episode, and total amount of clofazimine given. To describe the ENL episodes, the data was collected from monthly reviews and then summarized by ENL episodes. During this period, MB patients were only released from treatment after completing 24 monthly doses of MB-MDT. Patients receiving non-MB-MDT treatments had to complete at least two years of treatment and have a $\mathrm{BI}<2$ to be released from treatment.

Case definitions. Borderline lepromatous leprosy and lepromatous leprosy. These Ridley-Jopling classifications were determined clinically by the morphology of the skin lesions and pattern of nerve involvement, together with a BI, and were often supported by histologic examination of a skin biopsy specimen.

Case definition of ENL. The criterion for a diagnosis of ENL was the appearance of tender skin nodules. This could be accompanied by fever and other systemic symptoms such as joint pain, bone tenderness, neuritis, edema, malaise, anorexia, and/or lymphadenopathy. Patients with systemic symptoms but without typical ENL skin nodules were excluded from the study.

Treatment of ENL. All mild to severe episodes of ENL at the DLRC/BPRC were treated initially with a high dose of prednisolone that was tapered by $5 \mathrm{mg}$ per week. Patients with neuritis were treated with a monthly fixed steroid regimen that was reduced by $5 \mathrm{mg}$ each month. Tapering could last five months if the patient was treated with an initial dose of 25-40 mg of steroids.

Timing of ENL episodes. The end of an ENL episode was dated to the day when steroid tapering ended and if the patient did not have ENL and was not receiving prednisolone at the next review. An ENL episode was considered new if the interval between episodes was more than 15 days from not receiving steroids.

ENL definitions. The following case definitions were used. Single acute ENL was one ENL episode lasting less than six months with a steady decrease in steroid tapering, no recurrence of ENL when receiving prednisolone, and no increase in severity requiring an increased steroid dose. These patients also had no history of previous ENL. The criteria of six months had to be used as a cut-off because steroid tapering may take that long in the presence of neuritis. Acute multiple ENL was more than one ENL episode with the same characteristics as acute single ENL. Chronic ENL was an episode lasting for more than six months. This could include single and multiple episodes. Patients with only one ENL episode with a borderline duration (5-6 months) were considered as having chronic ENL if during the steroid tapering phase they developed fresh ENL when receiving prednisolone and the steroid dose had to be increased. Mixed acute and chronic ENL, which was observed in those patients with both acute and chronic ENL, was an episode lasting more than six months, but also some acute episodes (usually less than three months). These patients were added to the chronic ENL group for the comparison analysis.

Severity of ENL. The following scoring system was developed and applied to the cases. Very mild ENL was nonspecific signs and symptoms, one or two non-tender skin ENL nodules, low-grade fever or no fever, and undefined aches and pains. Mild ENL was few, mild, tender, skin nodules accompanied by low-grade fever, malaise, and systemic symptoms, e.g., joint pain. No ENL on steroids was the absence of signs and symptoms of ENL during steroid intake. Moderate ENL was mild ENL plus neuritis or more than three systemic symptoms. Severe ENL was illness with toxicity, multiple skin nodules, high-grade fever, dehydration, and other organ involvement such as orchitis, iritis, or severe neuritis. Intractable ENL was an episode of mild or moderate ENL while receiving $\geq 10 \mathrm{mg}$ of steroids. The following scores were assigned: $0=$ no ENL; 1 = very mild ENL; 2 = mild ENL; $3=$ no ENL on steroid therapy; $4=$ mild ENL on steroid therapy; $5=$ moderate ENL; $6=$ severe ENL; and $7=$ intractable ENL.

Highest severity during intake of the first 12 MB-MDT doses. Severity of ENL was categorized at each follow-up and the highest severity during the first 12 MB-MDT doses was recorded. This variable is an average of the highest severity among groups.

Treatment for ENL. Very mild ENL episodes were usually treated with aspirin or a non-steroidal anti-inflammatory drug or chloroquine for 10-15 days. All episodes of mild to severe ENL were treated with steroids and the dose was determined by the severity. Some patients with chronic ENL also received extra clofazimine.

Compliance. A coefficient of compliance was derived by dividing the number of monthly MDT doses taken by the number of months. Thus, the WHO recommended definition of compliance for an MB patient is taking 12 doses of MBMDT taken over an 18-month period, giving a coefficient of 0.67. Patients who took their 24 doses of MB-MDT over more than a 36-month period were defined as irregular. Compliance was only applied to patients with at least 12 months of follow-up data.

Duration of ENL. Total duration of ENL was calculated by adding all ENL episodes and ENL-free intervals between them for each patient. The MB-MDT duration was defined as the time period from the date of the first dose of MB-MDT until the date of the last dose.

Patients who had had previous ENL treated elsewhere were not counted for the timing of the first onset of ENL. The MB-MDT doses taken by patients before treatment at the DLRC/BPRC were added to the amount taken in these centers. Other treatments included dapsone monotherapy; paucibacillary-MDT; rifampicin, ofloxacin and minocycline; dapsone plus clofazimine; and clofazimine given by other hospitals, private practitioners, or village programs. 
Statistical analysis. Categorical data were tested for association using the chi-square test. The geometric mean was used when the data were skewed. Differences in means were tested using the Z-test. Both comparative analyses were done using STATA version 7 (Stata Corporation, College Station, TX) for multivariate logistic regression analysis. The exposure variables chosen for the multivariate analysis were based on the association found between them and the outcome of interest using the likelihood ratio test.

The data were used in three different analyses. The first analysis was a comparative analysis between cases with and without ENL to identify risk factors for developing ENL. Here the outcome definition was the presence of ENL, and subjects were divided into cases and controls. The second analysis was a descriptive comparison of the different types of ENL. The group data for each type of ENL was discussed and a typical detailed case history for each type was given with graphs showing the relationship between ENL severity, monthly MB-MDT taken, highest weekly prednisolone dose given, monthly cumulative prednisolone dose given, monthly clofazimine given, and BI. The third analysis was a comparison of cases with chronic versus acute multiple ENL to identify risk factors for each type. The ENL cases were subdivided into those with acute multiple ENL (cases) and chronic ENL (controls). The outcome was developing acute multiple ENL. The acute ENL category also included cases with recurrent acute ENL. The chronic ENL category combined cases whose ENL episodes that lasted for more than six months and those that had chronic and acute episodes. Only patients with at least one year of follow-up were included in this ENL comparison analysis.

\section{RESULTS}

Patient data. Four hundred eighty-one patients with LL and BL leprosy were treated at the DLRC/BPRC between January 1990 and December 2000 (LL, n = 180, 37.4\%; BL leprosy, $\mathrm{n}=301,62.6 \%)$. One hundred sixteen developed ENL. The overall prevalence of ENL in this cohort was $24.1 \%$, of whom $89(76.7 \%)$ were LL patients and $27(23.3 \%)$ were BL leprosy patients. The ENL prevalence among LL patients was $49.4 \%$ ( 89 of 180) and the ENL prevalence among BL leprosy patients was only $9.0 \%$ (27 of 301). Figure 1 shows the percentage of LL and BL leprosy cases developing ENL grouped by a BI $\geq 4$ or $<4$.

Risk factors for developing ENL. The ENL cases and BL leprosy/LL controls without ENL were compared to determine the risk factors for developing ENL (Table 1). Both groups had a similar age range at the time of leprosy diagnosis. (33.1 versus 31.7 years). Cases who developed ENL had significantly higher BIs at diagnosis $(3.5$ versus $2.0 ; P<0.001)$ and the onset of ENL than the non-ENL controls. The cases with ENL also had taken significantly more MDT (17.9 versus 12.0 months; $P<0.001)$ and for a longer time (24.7 versus 19.8 months). The two groups were similar in terms of compliance. The average compliance coefficient was 0.8 (95\% confidence

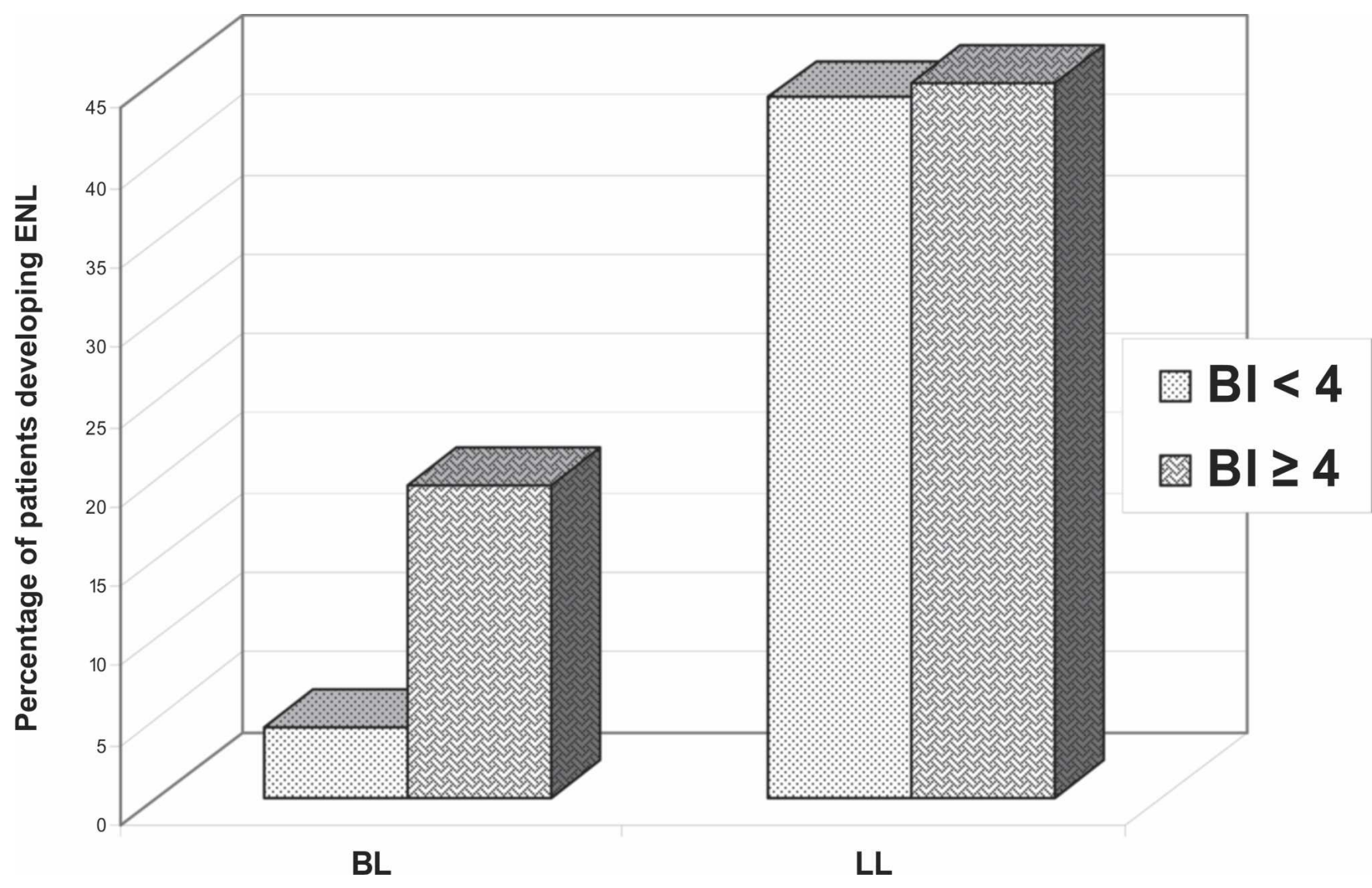

Figure 1. Leprosy type, bacterial index (BI), and erythema nodosum leprosum (ENL) at the Blue Peter Research Centre/Dhoolpet Leprosy Research Center, Hyderabad, India, 1990-2000. BL = borderline lepromatous leprosy; LL = lepromatous leprosy. 
TABLE 1

Comparison of means between ENL cases and non-cases at the DLRC/BPRC, Hyderabad, Andhra Pradesh, India, 1990-2000*

\begin{tabular}{|c|c|c|c|c|c|}
\hline & \multicolumn{2}{|c|}{ No ENL cases } & \multicolumn{2}{|c|}{ ENL cases } & \multirow{2}{*}{ Z-test } \\
\hline & Mean & $(95 \% \mathrm{CI})$ & Mean & $(95 \% \mathrm{CI})$ & \\
\hline Age, years & 33.1 & $(31.6-34.7)$ & 31.7 & $(29.2-34.5)$ & 0.220 \\
\hline BI at leprosy Dx & 2.0 & $(1.8-2.2)$ & 3.5 & $(3.2-3.8)$ & $<0.001$ \\
\hline $\mathrm{Bi}$ at ENL onset & 1.3 & $(1.0-1.5)$ & 2.7 & $(2.3-3.1)$ & $<0.001$ \\
\hline MB-MDT & 12.0 & $(11.1-12.9)$ & 17.9 & $(16.3-19.5)$ & $<0.001$ \\
\hline \multicolumn{6}{|l|}{ Time taking } \\
\hline $\begin{array}{l}\text { MB-MDT } \\
\text { (months) }\end{array}$ & 19.8 & $(17.6-21.9)$ & 24.7 & $(21.5-27.9)$ & 0.031 \\
\hline Compliance & 0.8 & $(0.7-0.8)$ & 0.8 & $(0.7-0.8)$ & 0.850 \\
\hline
\end{tabular}

interval $[\mathrm{CI}]=0.7-0.8$ ), which is equivalent to 24 monthly doses taken in 31.6 months or 12 monthly doses taken in 15.8 months. Table 2 summarizes the number and percentages of ENL cases and controls and the crude and adjusted odd ratios for all variables used in this analysis.

Logistic regression analysis. All variables were analyzed with logistic regression as main explanatory variables. When unadjusted ORs were obtained, the factors associated with
ENL were having $\mathrm{LL}$, a $\mathrm{BI} \geq 4$, and taking more than 24 monthly doses of MB-MDT. All had a $P$ value $\leq 0.001$.

A multivariate logistic regression model was constructed for each associated factor and all were adjusted by each other. We confirmed that having LL is a significant risk factor for developing ENL; LL patients were 8.4 times more likely to have ENL than BL leprosy patients $(95 \% \mathrm{CI}=4.6-15.4, P<$ 0.001). The Ridley-Jopling classification and BI at diagnosis were important determinants for ENL; LL patients with a BI $>4$ were 19 times more likely to have ENL than BL leprosy patients with a $\mathrm{BI}<4$. The $\mathrm{LL}$ patients with a $\mathrm{BI} \geq 4$ were only 3.2 times more likely to have ENL than BL patients with a $\mathrm{BI} \geq 4$. By comparison, $\mathrm{BL}$ patients with a $\mathrm{BI} \geq 4$ are 5.2 times more likely to have ENL than BL patients with a $\mathrm{BI}<$ 4. The LL patients with a $\mathrm{BI} \geq 4$ are as likely as LL patients with a BI $<4$ to have ENL. The ENL cases were 2.6 times more likely to have taken $\geq 24$ doses of MB-MDT than noncases $(95 \% \mathrm{CI}=1.1-6.3, P=0.025)$.

Different types of ENL and four typical cases Acute single ENL. Group data. Only five patients had an acute single episode of ENL. Four had received some treatment elsewhere before diagnosis at the DLRC/BPRC. All were men with an average age at diagnosis of 38.3 years (range $=23-$ 60). Three had BL leprosy and two had LL. The average BI at diagnosis was 2.1 (range $=0-4.66$ ). Two of them had a BI

TABle 2

Crude and adjusted odd ratios (ORs) comparing ENL cases versus non-cases at the DLRC/BPRC, Hyderabad, Andhra Pradesh, India, 1990-2000*

\begin{tabular}{|c|c|c|c|c|c|c|c|c|c|c|c|}
\hline Variables & No ENL & ENL cases & $\begin{array}{l}\text { Unadjusted } \\
\text { OR }\end{array}$ & $95 \% \mathrm{CI}$ & Wald $P$ & $\begin{array}{c}\text { Adjusted OR } \\
\text { ignoring } \\
\text { interaction }\end{array}$ & $95 \%$ CI & Irtest $P$ & $\begin{array}{c}\text { Adjusted } \\
\text { OR }\end{array}$ & $95 \% \mathrm{CI}$ & Irtest $P$ \\
\hline \multicolumn{12}{|c|}{ Age at diagnosis, years } \\
\hline$<35$ & $176 / 359(49.0)$ & 49/93 (52.7) & 1.0 & & & & & & & & \\
\hline$\geq 35$ & $183 / 359(51.0)$ & $44 / 93(47.3)$ & 0.9 & $0.5-1.4$ & 0.529 & & & & & & \\
\hline \multicolumn{12}{|l|}{ Sex } \\
\hline Male & 262/362 (72.4) & 69/93 (74.2) & 1.0 & & & & & & & & \\
\hline Female & $100 / 362(27.6)$ & $24 / 93(25.8)$ & 0.9 & $0.5-1.5$ & 0.726 & & & & & & \\
\hline \multicolumn{12}{|l|}{ Classification } \\
\hline BL (interaction: & & & & & & & & & & & \\
\hline LL if $\mathrm{BI}<4)$ & $275 / 365(75.3)$ & $25 / 93(22.6)$ & 1.0 & & & 1.0 & & & 19.0 & $8.0-45.2$ & $<0.001$ \\
\hline LL (interaction: & & & & & & & & & & & \\
\hline $\mathrm{LL}$ if $\mathrm{BI} \geq 4$ ) & $90 / 365$ (24.7) & 72/93 (77.4) & 10.5 & $6.1-18.0$ & $<0.001$ & 8.4 & $4.6-15.4$ & $<0.001$ & 3.2 & $1.5-7.0$ & 0.002 \\
\hline \multicolumn{12}{|l|}{$\begin{array}{c}\text { Bacterial index at } \\
\text { diagnosis }\end{array}$} \\
\hline $\begin{array}{r}<4 \text { (interaction: } \\
\mathrm{BI} \geq 4 \text { if } \mathrm{BL})\end{array}$ & 248/351 (70.7) & $35 / 93(37.6)$ & 1.0 & & & 1.0 & & & 5.2 & $2.1-12.9$ & 0.001 \\
\hline $\begin{array}{c}\geq 4 \text { (interaction: } \\
\mathrm{BI} \geq 4 \text { if } \mathrm{LL} \text { ) }\end{array}$ & 103/351 (29.3) & $58 / 93(62.4)$ & 4.0 & $2.5-6.4$ & $<0.001$ & 1.6 & $0.9-2.8$ & 0.105 & 0.8 & $0.4-1.6$ & 0.499 \\
\hline \multicolumn{12}{|c|}{$\begin{array}{l}\text { Total MB-MDT taken } \\
\text { at DLRC/BPRC, } \\
\text { days }\end{array}$} \\
\hline $1-23$ & 205/356 (57.6) & 28/93 (30.1) & 1.0 & & & 1.0 & & & NA & & \\
\hline$\geq 24$ & $151 / 356(42.4)$ & $65 / 93(69.9)$ & 2.3 & $1.4-3.7$ & 0.001 & 2.6 & $1.1-6.3$ & 0.025 & & & \\
\hline \multicolumn{12}{|c|}{$\begin{array}{l}\text { Total time taking MB- } \\
\text { MDT at DLRC/ } \\
\text { BPRC, days }\end{array}$} \\
\hline $1-23$ & 215/351 (61.3) & 45/91 (49.5) & 1.0 & & & 1.0 & & & & & \\
\hline$\geq 24$ & $136 / 351(38.8)$ & $46 / 91(50.5)$ & 1.6 & $1.0-2.6$ & 0.042 & 0.9 & $0.4-2.0$ & 0.767 & & & \\
\hline \multicolumn{12}{|l|}{ WHO compliance } \\
\hline Regular & 244/333 (73.3) & 70/90 (77.8) & 1.0 & & & & & & & & \\
\hline Irregular & $89 / 333(26.7)$ & $20 / 90(22.2)$ & 0.8 & $0.5-1.4$ & 0.387 & & & & & & \\
\hline
\end{tabular}


of 0 . One had been treated with dapsone monotherapy for five years and the other received only two monthly MB-MDT doses. The average MB-MDT taken was 20.8 monthly doses (range $=17-24$ ). Three of them had ENL at diagnosis. The other two developed ENL between three and six months after starting treatment at the BPRC/DLRC. The average highest prednisolone dose given to these patients per month was 22 $\mathrm{mg}$, and the total amount of prednisolone given for this single episode ranged from $210 \mathrm{mg}$ to $2.310 \mathrm{mg}$.

Typical acute single ENL case. Figure 2 shows the only case with no previous leprosy treatment. This 50-year-old man had a BI at diagnosis of 4.66 and came to the clinic with ENL. His ENL was mild and he was treated with prednisolone, $15 \mathrm{mg}$ for one week, and tapered by $5 \mathrm{mg}$ per week. The episode lasted 21 days.

Acute Multiple ENL. Group data. Twenty-six patients had acute multiple ENL. Twenty-three had LL and three had BL leprosy. The mean age of this group was 32 years (range = $8-55)$. The average BI at diagnosis was 3.5 and 2.7 , respectively, at the time of the first ENL episode. The average time from starting treatment at the DLRC to onset of ENL was seven months (range $=0-24$ ). The average number of ENL episodes was 3.4 (range $=2-10$ ). The average time from first ENL episode to the last one was 12 months. The average total MBMDT monthly doses taken was 18 (minimum $=6$, maximum $=26$ ). The average coefficient of compliance was 0.6 , which was equivalent to $12 \mathrm{MB}-\mathrm{MDT}$ doses in 20 months or 24/40.

Case history. Figure 3 shows data of a patient with acute recurrent or multiple ENL. This 45-year-old man had LL and a BI at diagnosis of 4.3. The first leprosy symptoms were noticed by the patient three years earlier. He developed ENL 15 days after starting MB-MDT. This was a mild ENL with neuritis, classified here as moderate ENL. The highest daily prednisolone dose given to this patient was $25 \mathrm{mg}$ in the first episode.

He had nine more episodes of acute ENL of similar severity over the next 30 months. He took 25 monthly MB-MDT over a 40-month period, but very irregularly in the last half of treatment. After a self-break from treatment, he had only 2 ENL episodes separated from each other by a period of 23 weeks. He had a BI of 0.5 three years after diagnosis and 0.0 two years later. He was followed-up for six years and has had no additional ENL episodes.

Chronic ENL. Group data. There were 55 patients (13 with BL leprosy and 36 with LL) with chronic ENL; 18 had only chronic ENL episodes and 37 had mixed episodes of acute and chronic ENL. The average age at diagnosis in this group was 31.9 years (range $=12-62$ ). The mean BI was 3.7 at diagnosis and 3.1 at onset of ENL. These patients had an average of 2.3 years of reported symptomatic leprosy before treatment started. The average onset of ENL was 2.3 months after starting MB-MDT at the DLRC/BPRC (range =0-6). The average number of ENL episodes was 2.8 (minimum $=$ 1 , maximum $=10$ ). The mean total length of ENL duration was 18 months and that of MB-MDT was 20 doses (range = 0-25 MB-MDT doses; the minimum value of 0 is for a patient who had 24 MB-MDT doses at another facility and was referred for management of ENL). The compliance coefficient was 0.8 , which is equivalent to 12 doses in 15 months or 24/30.

Case history. Figure 4 shows the clinical data for a 30 -yearold untreated man with BL with LL. At diagnosis, he had neuritis and was given MB-MDT plus extra clofazimine and prednisolone for one month. Two months later, he developed neuritis again accompanied by dactylitis, arthralgia, bone tenderness, and edema of both feet. He had no skin nodules or fever. He was started on prednisolone $20 \mathrm{mg}$, but one week later it had to be increased to $30 \mathrm{mg}$ because of the severity of the symptoms. It was tapered monthly over a four-month period and ENL reappeared when he reached a prednisolone dose $10 \mathrm{mg}$. Six and a half months later, he developed fever, skin nodules, arthritis, neuritis, and bone tenderness after stopping prednisolone for four days. He then had continuous ENL with periods off prednisolone of less than 15 days. When prednisolone was stopped, the patient developed severe ENL that became intractable with symptoms when he was taking prednisolone that included neuritis, red and painful eyes,

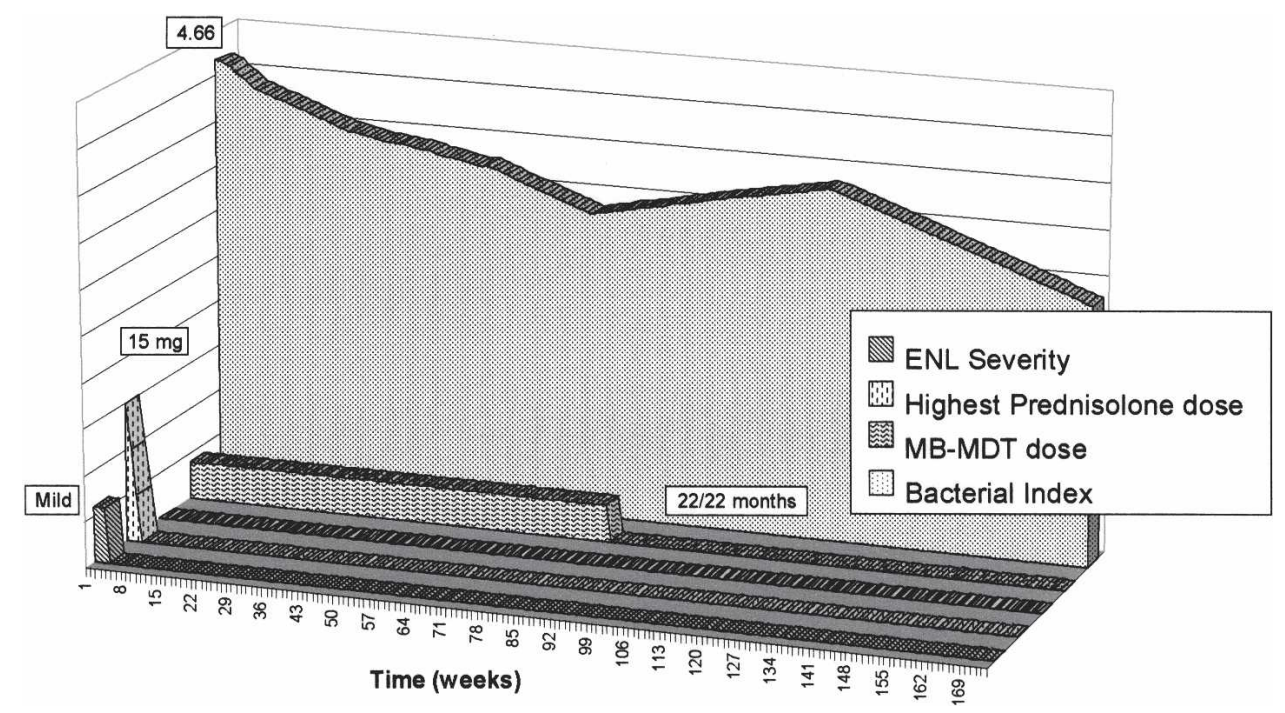

Figure 2. Clinical indices in a typical case of acute, single erythema nodosum leprosum (ENL) at the Blue Peter Research Centre/Dhoolpet Leprosy Research Center, Hyderabad, India, 1990-2000. MB-MDT = multi-drug therapy for multibacillary leprosy. 


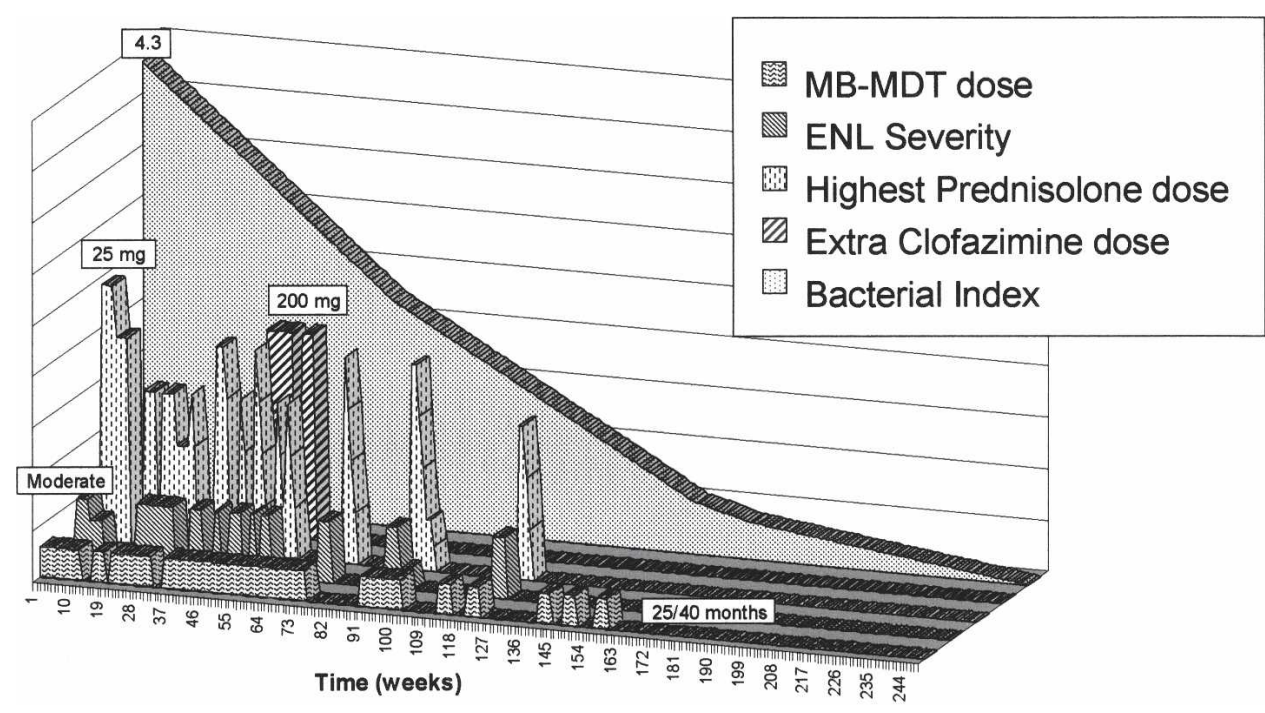

FIGURE 3. Clinical indices in a typical case of acute, multiple erythema nodosum leprosum (ENL) at the Blue Peter Research Centre/Dhoolpet Leprosy Research Center, Hyderabad, India, 1990-2000. MB-MDT = multi-drug therapy for multibacillary leprosy.

bone tenderness, and joint pains. The patient had been advised to decrease his prednisolone dose, but he bought more steroids and was probably taking even higher doses for some unquantified periods. The ENL was uncontrolled when his prednisolone dose was less than $15 \mathrm{mg} /$ day. When he completed MDT, clofazimine was then given alone at a higher dose and the steroids were then tapered successfully. This patient took at least $15,580 \mathrm{mg}$ of prednisolone over a 31 month period, but no side effects were reported. This patient took 25 monthly MB-MDT doses in 28 months (coefficient = 0.89). His BI was 4.33 at diagnosis, 2.83 one year later, and 4.0 two years later, and then decreased to 1.0.

Figure 5 shows data of a patient with chronic ENL and a mixed pattern of acute and chronic episodes. She was a 25year-old woman with BL leprosy. She was diagnosed in 1994, but defaulted until 1997, when she observed with mild ENL and not received any MDT. Her BI was 3.0 in 1997, and it increased to 4.25 one and a half year later, but decreased rapidly to 0.6 the following year. She was initially treated with prednisolone, $25 \mathrm{mg}$, for one month, which was tapered to 20 $\mathrm{mg}$ for another month because of accompanying nerve damage. She then re-presented with ENL and was receiving $20 \mathrm{mg}$ of prednisolone. She then required intermittent high doses of prednisolone over the first eight months of her treatment. The steroid tapering was particularly difficult in this patient because she received relatively high doses and failed to attend her follow-up reviews.

The patient started regularly attending her follow-up reviews after the eighth MB-MDT dose and her ENL then became continuous. She received additional clofazimine, 200 $\mathrm{mg}$ /day, from her 12th to 24th dose of MB-MDT and had only one additional episode of severe ENL. She had mild ENL

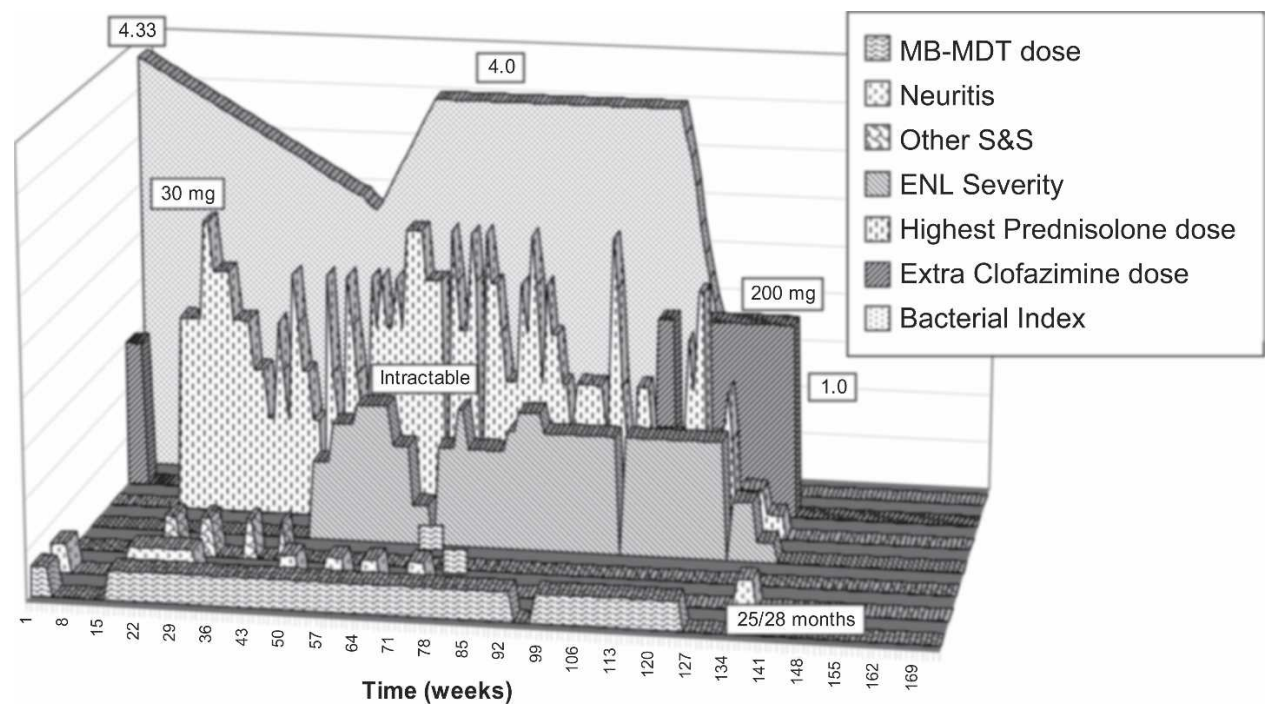

FIGURE 4. Clinical indices in a typical case of chronic erythema nodosum leprosum (ENL) at the Blue Peter Research Centre/Dhoolpet Leprosy Research Center, Hyderabad, India, 1990-2000. MB-MDT = multi-drug therapy for multibacillary leprosy; S \& S = signs and symptoms; $\mathrm{BI}=$ bacterial index.. 


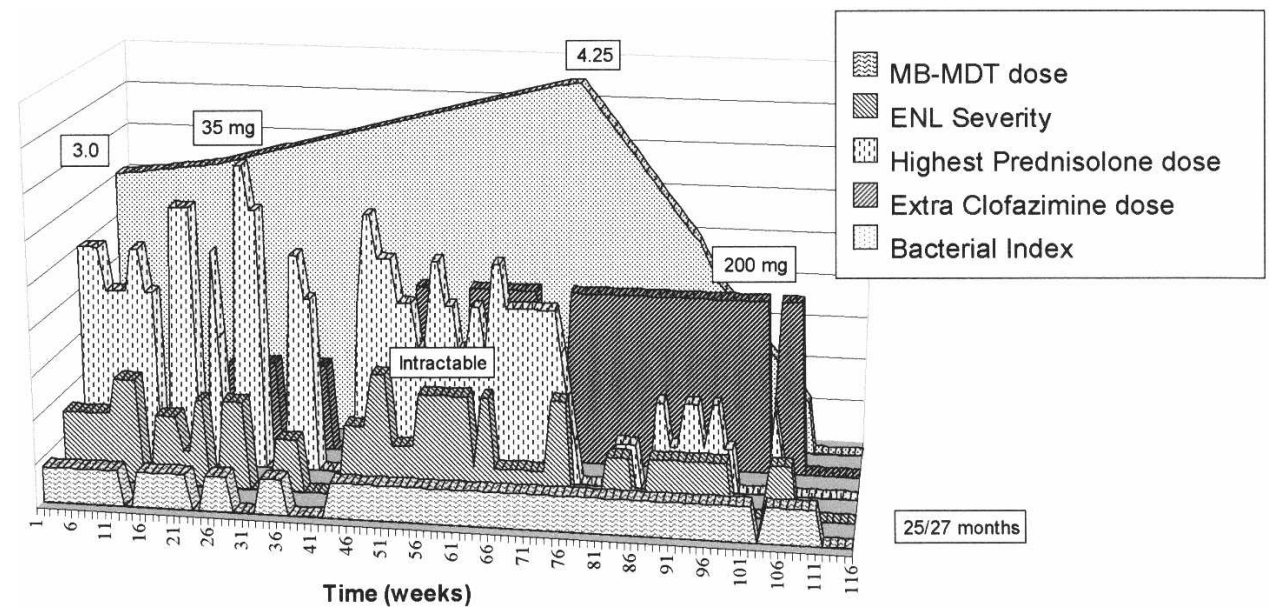

FIGURE 5. Clinical indices in a typical case of mixed acute and chronic erythema nodosum leprosum (ENL) at the Blue Peter Research Centre/Dhoolpet Leprosy Research Center, Hyderabad, India, 1990-2000. MB- MDT = multi-drug therapy for multibacillary leprosy.

that required 5 or $10 \mathrm{mg}$ of prednisolone a day until completing her chemotherapy. Her ENL can be summarized as ranging from intractable to no ENL while receiving steroids; after receiving extra clofazimine she had milder ENL.

Comparison between chronic and acute multiple ENL. Acute multiple and chronic forms of ENL are compared in Table 3. Of the original cohort of 116 patients, 28 were excluded because they had too short a follow-up and could not be categorized. The remaining 88 patients were grouped into $33(37.5 \%)$ with acute multiple ENL and 55 (62.5\%) with chronic ENL. The group with acute ENL included 7 patients with acute single ENL and 26 with acute multiple ENL. The group with chronic ENL included 18 patients with chronic ENL and 37 patients with mixed ENL. The two groups were similar for age, sex, Ridley-Jopling classification, BI at diag- nosis, previous anti-leprosy treatment, total number of ENL episodes, and amount of MB-MDT (all with $P>0.05$, for means and categorical data).

The mean BI at diagnosis was 3.5 (95\% CI $=3.3-3.9$, range $=0-6)$. Both groups had symptoms of leprosy for three years before diagnosis $(95 \% \mathrm{CI}=2.1-3.6)$. The ENL in both groups started soon (3.7 months) after starting treatment. The average number of ENL episodes was 3.1 (95\% CI $=2.7-3.5$, range $=1-10)$. The average $\mathrm{MB}-\mathrm{MDT}$ taken was 18.5 monthly doses in both groups.

The patients with chronic ENL had a longer average duration of disease (16.9 months) than patients with acute multiple ENL (10.7 months) $(P=0.049)$. Thirty-one $(67.4 \%)$ of 46 patients had chronic ENL for more than 12 months and 18 $(54.6 \%)$ of 33 patients had acute multiple ENL for less than

TABLE 3

Comparison of means for chronic and acute multiple ENL at the DLRC/BPRC, Hyderabad, Andhra Pradesh, India, 1990-2000*

\begin{tabular}{|c|c|c|c|c|c|c|c|}
\hline & \multicolumn{2}{|r|}{ All ENL cases } & \multicolumn{2}{|c|}{ Cases with chronic ENL } & \multicolumn{2}{|c|}{ Cases with acute ENL } & \multirow{2}{*}{$\stackrel{t \text {-test }}{P}$} \\
\hline & $\mathrm{n}$ & Mean $(95 \% \mathrm{CI})$ & $\mathrm{n}$ & Mean $(95 \% \mathrm{CI})$ & $\mathrm{n}$ & Mean $(95 \% \mathrm{CI})$ & \\
\hline ENL onset (months) & 43 & $3.7(2.2-5.2)$ & 26 & $2.8(1.4-4.1)$ & 17 & $5.1(1.8-8.4)$ & 0.128 \\
\hline Total ENL episodes & 88 & $3.2(2.7-3.5)$ & 55 & $3.0(2.5-3.5)$ & 33 & $3.3(2.5-3.1)$ & 0.481 \\
\hline Total ENL duration (months) & 79 & $18.5(15.4-21.5)$ & 46 & $21.0(17.3-24.7)$ & 33 & $14.9(9.7-20.1)$ & 0.049 \\
\hline First ENL episode duration (days) & 72 & $154(112-196)$ & 46 & $207.5(148-267)$ & 26 & $59(38-80)$ & 0.004 \\
\hline Second ENL episode duration (days) & 60 & $108(66-149)$ & 35 & $148(80-216)$ & 25 & $51(34-68)$ & 0.012 \\
\hline Total duration of MB-MDT intake (months) & 86 & $25.6(22.8-28.6)$ & 53 & $22.5(20.0-25.0)$ & 33 & $30.5(24.8-36.3)$ & 0.004 \\
\hline ENL duration/MB-MDT duration & 39 & $0.7(0.6-0.8)$ & 22 & $0.8(0.6-0.9)$ & 17 & $0.6(0.4-0.7)$ & 0.085 \\
\hline Compliance coefficient & 86 & $0.8(0.7-0.8)$ & 53 & $0.9(0.8-0.9)$ & 33 & $0.7(0.6-0.8)$ & 0.001 \\
\hline Compliance during first $6 \mathrm{MB}-\mathrm{MDT}$ & 82 & $0.8(0.8-0.9)$ & 50 & $0.9(0.8-0.9)$ & 32 & $0.7(0.6-0.8)$ & 0.013 \\
\hline Compliance during second 6 MB-MDT & 69 & $0.9(0.8-0.9)$ & 46 & $0.9(0.9-1.0)$ & 23 & $0.8(0.7-0.9)$ & 0.060 \\
\hline Compliance during after first $12 \mathrm{MB}-\mathrm{MDT}$ & 56 & $0.8(0.8-0.9)$ & 36 & $0.9(0.8-0.9)$ & 20 & $0.8(0.6-0.9)$ & 0.087 \\
\hline ENL severity & 65 & $2.4(1.1-2.5)$ & 39 & $3.2(2.7-3.6)$ & 26 & $1.3(0.8-1.8)$ & $<0.001$ \\
\hline First ENL episode severity & 88 & $3.0(2.6-3.4)$ & 55 & $3.3(2.8-3.7)$ & 33 & $2.6(1.9-3.3)$ & 0.116 \\
\hline Overall severity related to MB-MDT intake & 65 & $2.4(2.0-2.8)$ & 39 & $3.2(2.7-3.6)$ & 26 & $1.3(0.8-1.8)$ & $<0.001$ \\
\hline Severity during first 6 MB-MDT doses intake & 81 & $2.6(2.3-2.9)$ & 49 & $3.2(2.9-3.6)$ & 32 & $1.7(1.2-2.1)$ & $<0.001$ \\
\hline Severity during second 6 MB-MDT doses intake & 72 & $2.5(2.1-2.9)$ & 46 & $3.1(2.7-3.5)$ & 26 & $1.4(1.0-1.9)$ & $<0.001$ \\
\hline Severity after first 12 MB-MDT doses intake & 71 & $2.6(2.3-2.9)$ & 45 & $3.2(2.9-3.5)$ & 26 & $1.5(1.1-1.9)$ & $<0.001$ \\
\hline Severity after completion of MB-MDT & 45 & $0.9(0.5-1.3)$ & 30 & $1.2(0.7-1.8)$ & 15 & $0.1(0.0-0.3)$ & 0.006 \\
\hline Highest severity during first $12 \mathrm{MB}-\mathrm{MDT}$ doses & 86 & $5.4(5.1-5.8)$ & 53 & $5.9(5.7-6.2)$ & 33 & $4.6(4.0-5.2)$ & $<0.001$ \\
\hline Severity before clofazimine intake & 40 & $3.9(3.5-4.3)$ & 31 & $4.0(3.6-4.4)$ & 9 & $3.4(2.4-4.5)$ & 0.226 \\
\hline Severity during clofazimine intake & 40 & $2.8(2.4-3.2)$ & 31 & $3.1(2.7-3.5)$ & 9 & $1.7(1.0-2.5)$ & 0.002 \\
\hline Severity after clofazimine intake & 28 & $0.9(0.4-1.4)$ & 20 & $1.0(0.3-1.8)$ & 8 & $0.6(0.0-1.2)$ & 0.410 \\
\hline Prednisolone per month & 74 & $337(264-411)$ & 43 & $421(308-533)$ & 31 & $222(155-289)$ & 0.007 \\
\hline
\end{tabular}

* For definition of abbreviations, see Table 1 . Bold $P$ values indicate statistical significance. 
12 months. Thirty (65\%) of 46 patients with chronic ENL had an overall disease duration that lasted $\geq 75 \%$ of the total MB-MDT intake duration and 24 (73\%) of 33 patients with acute multiple ENL had an overall disease duration that lasted $<75 \%$ of the total MB-MDT intake duration.

Overall compliance for cases with chronic ENL was more regular than for patients with acute ENL $(P=0.001)$. Compliance during first six MB-MDT doses was more regular among case with chronic ENL than in cases with acute ENL, but was similar in both groups during the rest of the MBMDT intake period (Figure 6).

When we compared patients with chronic ENL with those with acute multiple ENL, we found that those with chronic ENL had a higher average prednisolone monthly dose (421 $\mathrm{mg} / \mathrm{month})$ than those with acute multiple ENL (222 mg/ month) $(P=0.007)$, a higher severity score $(2.5$ versus 1.8$)$ $(P=0.072)$ for the duration of ENL, and a disease that was more difficult to control. Forty-five percent with chronic disease continued to have ENL (more than mild) while taking prednisolone compared with $23 \%$ in those with acute multiple ENL. Twenty-one (54\%) of 39 patients with chronic ENL had an overall mean severity $\geq 3$ during MB-MDT intake compared with one patient with acute multiple ENL.

Table 3 shows the sequential severity scores for patients with chronic ENL and those with and acute multiple ENL. The severity score was highest at the start of ENL in both groups (3.2 versus 1.3 ) and decreased more slowly in patients with chronic ENL. The severity scores were significantly higher at each time point in patients with chronic ENL $(P<$ 0.001) (Figure 7). Thirty-three $(67 \%)$ of 49 patients with chronic ENL had a severity score $\geq 3$ during the first $6 \mathrm{MB}$ MDT doses compared with $2(6 \%)$ of 32 patients with acute multiple ENL. These figures were 65\% (30 of 46) and 8\% (2 of 26), respectively, for the second six months of MDT and $46 \%$ (18 of 39) and 4\% (1 of 24) for the second 12 months of MDT.

We used this data set to assess the effectiveness of clofazimine in controlling ENL. Forty $(45.5 \%)$ patients (9 with acute multiple ENL and 31 with chronic ENL) received extra clofazimine for $\geq 4$ months. The mean severity score before additional clofazimine was 4.0 for patients with chronic ENL and 3.4 for patients with acute ENL $(P=0.226)$. This decreased to 3.1 and $1.7(P=0.002)$, respectively, during clofazimine intake and to 1.0 and $0.6(P=0.410)$, respectively, after clofazimine intake, indicating that the drug probably ameliorates ENL. However, clofazimine was used late in treatment, with $64.5 \%$ of patients with chronic ENL starting their extra clofazimine after the sixth MB-MDT dose compared with $89 \%$ of the patients with acute multiple ENL who started it during the first six months of chemotherapy.

Patients with acute and chronic ENL were compared by logistic regression analysis. Table 4 summarizes the number and percentages of patients with chronic and acute multiple ENL and the crude and adjusted ORs by the analysis variables. All variables were checked with logistic regression as main explanatory variables. When unadjusted ORs were obtained, the factors associated with chronic ENL were being less than 35 years of age $(P=0.031)$, more severe ENL $(P=$ $0.037)$, ENL lasting $\geq 75 \%$ that of the MB-MDT duration $(P=0.001)$, developing severe ENL during first $12 \mathrm{MB}-\mathrm{MDT}$ doses $(P<0.001)$, regular MB-MDT compliance during first six doses $(P<0.001)$, regular MB-MDT compliance from the 13th dose to release from treatment $(P=0.014)$, overall regular compliance $(P<0.001)$, higher severity during the first six MB-MDT doses, the second six MB-MDT doses, and the rest of the MB-MDT doses $(P<0.001$ for all $)$, and higher severity during additional intake of clofazimine.

Logistic regression was done for each associated factor. When the effect of these variables was adjusted by the other risk factors and other cofounders, an association was found between chronic ENL and overall ENL severity and severity during first $6 \mathrm{MB}-\mathrm{MDT}$ doses. Being $\geq 35$ years of age and irregular MB-MDT compliance (overall and during first six doses) protected against development of chronic ENL. (All < 0.008 , except overall severity $P<0.05$ ).

Patients with acute multiple ENL were more likely to be

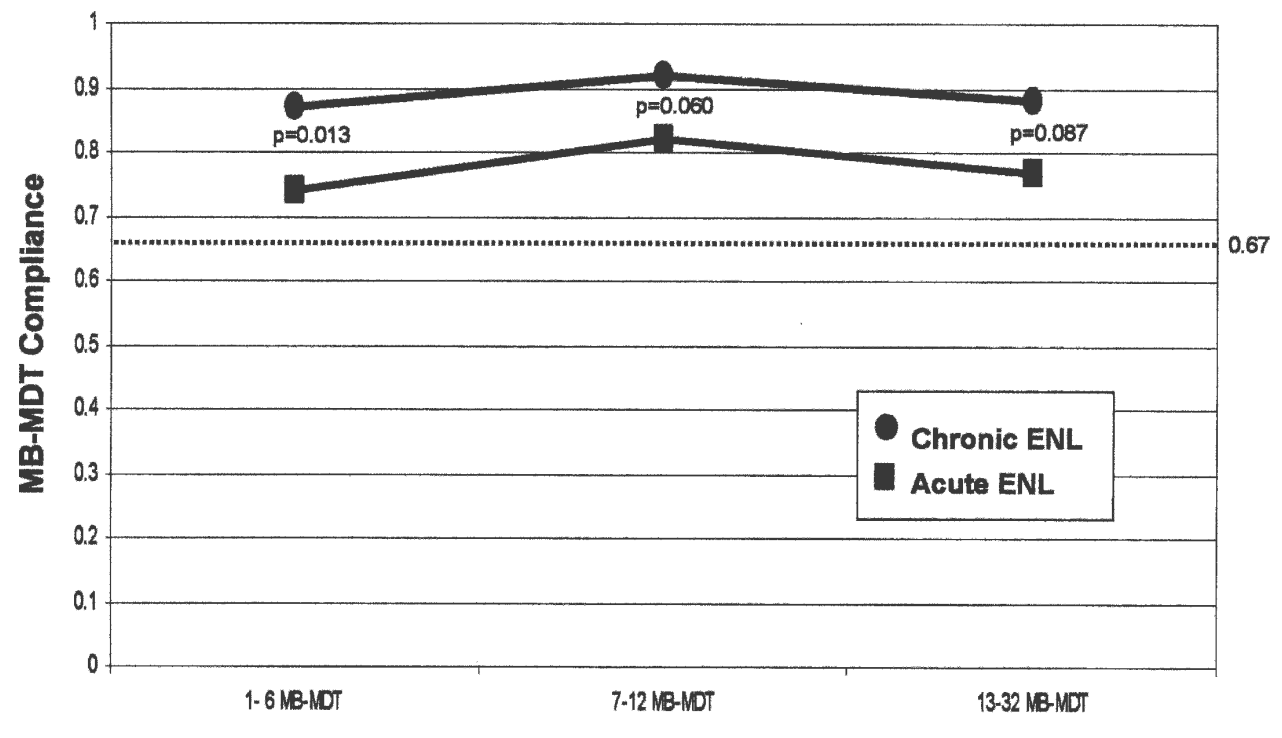

MB-MDT Intake Periods

FIGURE 6. Compliance with multi-drug therapy for multibacillary leprosy (MB-MDT) in patients with acute and chronic erythema nodosum leprosum (ENL) types. The dotted line indicates the World Health Organization compliance coefficient of 0.67. 


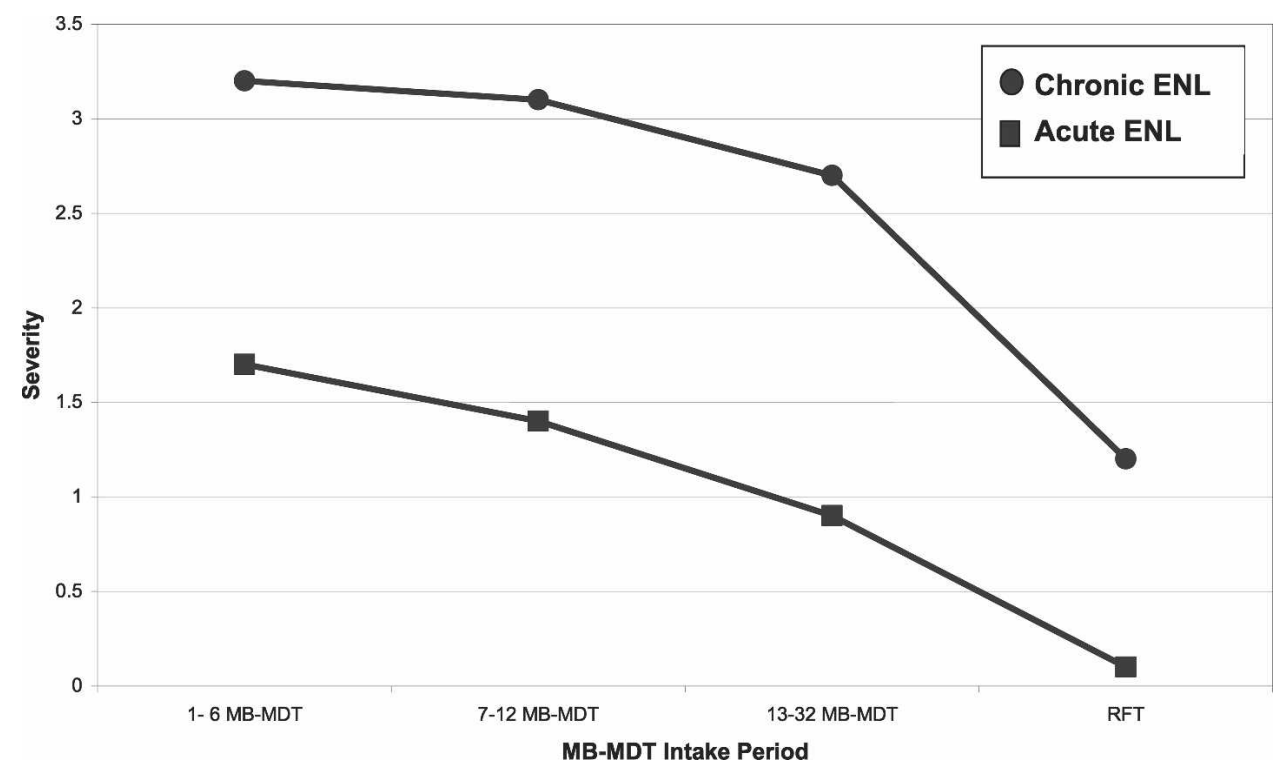

FIGURE 7. Mean severity versus time intake by erythema nodosum leprosum (ENL) type. MB-MDT = multi-drug therapy for multibacillary leprosy. RFT $=$ released from treatment.

receiving irregular treatment or non-compliant than patients with chronic ENL $(\mathrm{OR}=0.1,95 \% \mathrm{CI}=0.001-0.05, P=$ 0.002). Those with chronic ENL were 3.2 times more likely to develop moderate to severe ENL than those with acute ENL $(95 \% \mathrm{CI}=1.0-10.8, P=0.047)$ and 8.2 times more likely to develop any type of ENL than those with acute ENL (95\% CI $=0.8-85.5, P=0.042$ ).

Analysis of the severity during first six months of MB-MDT showed that patients with chronic ENL were 29 times more likely to develop any type of ENL than patients with acute ENL (95\% CI $=4.3-197.2, P<0.001)$. Patients with chronic ENL were 15 times more likely to develop any type of ENL than those with acute ENL during the second six MB-MDT doses $(95 \% \mathrm{CI}=2.3-89.5, P<0.001)$. The difference in overall severity and severity related to MB-MDT intake may be the result of most patients with acute ENL stopping treatment for some time, which decreased their ENL severity compared with chronic cases who were more regular with their treatment.

\section{DISCUSSION}

This is the first study to report long-term disease patterns in ENL and the largest reported cohort of patients (116) with ENL from a large, well-documented patient base. It is surprising that $49 \%$ of the patients with LL had an episode of ENL. However, since the DLRC/BPRC is a referral center, more complex cases will be referred there. We are confident that this is a true prevalence because we reviewed information of all cases of BL leprosy and LL. A prevalence of $50 \%$ of LL patients having ENL in the dapsone monotherapy era is widely cited ${ }^{1}$ and there is a consensus that the prevalence of ENL has decreased since the introduction of MDT. However, we could not find any published data from India on the current prevalence of ENL in patients who were treated with WHO-MB-MDT. There may be regional differences in the prevalence of ENL. Becx-Bleuminck and Berhe ${ }^{8}$ reported that only $5 \%$ of MB patients in Ethiopia treated with MDT had ENL, and Saunderson and others ${ }^{11}$ reported a similar low figure in an Ethiopian cohort study on MDT and reactions. Nery and others ${ }^{6}$ found that $58 \%$ of LL patients in Brazil were reported as having ENL. The reduction in the incidence of ENL is attributed to the anti-inflammatory action of the clofazimine component of MDT. Earlier diagnosis when fewer patients have high BIs would also help reduce the incidence of ENL.

Cellona and others ${ }^{5}$ compared different MDT regimens and found that patients taking clofazimine-containing regimens were less likely to experience ENL than those not taking clofazimine, with rates of ENL of $14-21 \%$ versus $24-45 \%$, respectively, after 12 months. Chattopadhyay and others ${ }^{12}$ compared clofazimine with ethionamide and found that patients treated with clofazimine had both fewer ENL reactions (30\% versus $50 \%)$ and superior bacterial clearance, $(25.8 \%$ versus $4.5 \%$ negativity by end of study). Clearly, not all patients are protected from ENL by clofazimine at the $50 \mathrm{mg} /$ day dosage used in MB-MDT. The difference we found between the prevalence of ENL in BL versus LL patients is striking. We confirmed that having LL is the most important risk factor for developing ENL. (OR $=8.4, P<0.001)$. Although BI was not a risk factor per se, patients with BL leprosy with a $\mathrm{BI} \geq 4$ are also at risk $(\mathrm{OR}=5.2, P=0.001){ }^{1,2}$

Since this was a retrospective study we were not able to collect reliable data on the clinical features of ENL in our clinic. This requires a prospective cohort study with systematic clinical examinations being performed on each patient. Also, we were able to compile only a simple scale indicating the severity of the ENL. The data on the response to treatment is also limited, with the amount of steroids needed by each patient as a surrogate marker of severity. This is another feature that should be studied in a prospective study. This study shows that ENL is a serious event because $92 \%$ of these patients experienced multiple episodes of ENL over a period of 14 months. The average age of the patients with ENL was 34.7 years, an age when they might be expected to be most productive economically. A two-year period of chronic re- 
TABLE 4

Frequency, percentages, crude and adjusted odd ratios (ORs) comparing acute ENL versus chronic ENL at the DLRC/BPRC, Hyderabad, Andra Pradesh, India, 1990-2000*

\begin{tabular}{|c|c|c|c|c|c|c|c|c|c|c|c|}
\hline \multirow[b]{2}{*}{ Variables } & \multicolumn{2}{|c|}{ Acute ENL } & \multicolumn{2}{|c|}{ Chronic ENL } & \multirow{2}{*}{$\begin{array}{l}\chi^{2} \text { or } \\
\text { Fisher } \\
\text { exact } P\end{array}$} & \multirow{2}{*}{$\begin{array}{l}\text { Crude } \\
\text { OR }\end{array}$} & \multirow[b]{2}{*}{$95 \% \mathrm{CI}$} & \multirow{2}{*}{$\begin{array}{l}\text { Wald } \\
\text { test } P\end{array}$} & \multirow{2}{*}{$\begin{array}{l}\text { Adjusted } \\
\text { OR }\end{array}$} & \multirow[b]{2}{*}{$95 \% \mathrm{CI}$} & \multirow{2}{*}{$\begin{array}{l}\text { Likelihood } \\
\text { ratio test } P\end{array}$} \\
\hline & No. & $\%$ & No. & & & & & & & & \\
\hline \multicolumn{12}{|l|}{ Age at diagnosis, years } \\
\hline$<35$ & $12 / 33$ & 36.4 & $33 / 55$ & 60.0 & & 1.0 & & & 1.0 & & \\
\hline$\geq 35$ & $21 / 33$ & 63.6 & $22 / 55$ & 40.0 & 0.032 & 0.4 & $(0.2-0.9)$ & 0.034 & 0.2 & $(0.04-0.7)$ & 0.007 \\
\hline \multicolumn{12}{|l|}{ Ridley-Joppling classification } \\
\hline Borderline lepromatous & $7 / 33$ & 21.2 & $14 / 55$ & 25.5 & & 1.0 & & & & & \\
\hline Lepromatous leprosy & $26 / 33$ & 78.8 & $41 / 55$ & 74.5 & 0.651 & 0.8 & $(0.3-2.2)$ & 0.649 & & & \\
\hline \multicolumn{12}{|l|}{ Bacterial index at leprosy diagnosis } \\
\hline$<4$ & $15 / 33$ & 45.5 & $18 / 55$ & 32.7 & & 1.0 & & & & & \\
\hline$\geq 4$ & $18 / 33$ & 54.5 & $37 / 55$ & 67.3 & 0.233 & 1.7 & $(0.7-4.2)$ & 0.234 & & & \\
\hline \multicolumn{12}{|l|}{ Overall severity } \\
\hline Mild ENL & $24 / 31$ & 77.4 & $28 / 51$ & 54.9 & & 1.0 & & & 1.0 & & \\
\hline Moderate to severe ENL & $7 / 31$ & 22.6 & $23 / 51$ & 45.1 & 0.040 & 2.8 & $(1.0-7.7)$ & 0.037 & 3.2 & $(1.0-10.8)$ & 0.047 \\
\hline \multicolumn{12}{|l|}{ Total ENL duration, months } \\
\hline$\leq 12$ & $18 / 33$ & 54.5 & $15 / 46$ & 32.6 & & 1.0 & & & 1.0 & & \\
\hline$>12$ & $15 / 33$ & 45.5 & $31 / 46$ & 67.4 & 0.051 & 2.5 & $(1.0-6.2)$ & 0.051 & 3.1 & $(0.7-3.1)$ & 0.120 \\
\hline \multicolumn{12}{|l|}{ ENL/MB-MDT duration } \\
\hline ENL duration $<75 \%$ of MB-MDT duration & $24 / 33$ & 72.7 & $16 / 46$ & 34.8 & & 1.0 & & & 1.0 & & \\
\hline ENL duration $\geq 75 \%$ of MB-MDT duration & 9/33 & 27.3 & $30 / 46$ & 65.2 & 0.001 & 5.0 & $(1.9-13.3)$ & 0.001 & 4.2 & $(0.7-26.1)$ & 0.107 \\
\hline \multicolumn{12}{|l|}{ WHO compliance } \\
\hline Regular & $18 / 31$ & 58.1 & $49 / 53$ & 92.5 & & 1.0 & & & 1.0 & & \\
\hline Irregular & $13 / 31$ & 49.1 & $4 / 53$ & 7.5 & $<0.001$ & 0.1 & $(0.03-0.4)$ & $<0.001$ & 0.1 & $(0.01-0.5)$ & 0.002 \\
\hline \multicolumn{12}{|l|}{ Compliance during first $6 \mathrm{MB}-\mathrm{MDT}$ intake } \\
\hline Regular & $19 / 32$ & 59.4 & $46 / 50$ & 92.0 & & 1.0 & & & 1.0 & & \\
\hline Irregular & $13 / 32$ & 40.6 & $4 / 50$ & 8.0 & 0.001 & 0.1 & $(0.04-0.4)$ & $<0.001$ & 0.1 & $(0.01-0.5)$ & 0.002 \\
\hline \multicolumn{12}{|l|}{ Overall severity during MB-MDT intake } \\
\hline None & $25 / 26$ & 96.1 & $18 / 39$ & 46.2 & & 1.0 & & & 1.0 & & \\
\hline Some & $1 / 26$ & 3.9 & $21 / 39$ & 53.8 & $<0.001$ & 29.2 & $(3.6-237)$ & $<0.001$ & 8.2 & $(0.8-85.5)$ & 0.042 \\
\hline \multicolumn{12}{|l|}{ Severity during first $6 \mathrm{MB}-\mathrm{MDT}$ intake } \\
\hline None & $30 / 32$ & 93.8 & $16 / 49$ & 32.6 & & 1.0 & & & 1.0 & & \\
\hline Some & $2 / 32$ & 6.2 & $33 / 49$ & 67.4 & $<0.001$ & 30.9 & $(6.6-146)$ & $<0.001$ & 29.1 & $(4.3-197)$ & $<0.001$ \\
\hline Severity during second 6 MB-MDT intake & & & & & & & & & & & \\
\hline None & $24 / 26$ & 92.3 & $16 / 46$ & 34.8 & & 1.0 & & & 1.0 & & \\
\hline Some & $2 / 26$ & 7.7 & $30 / 46$ & 65.2 & $<0.001$ & 22.5 & $(4.7-108)$ & $<0.001$ & 15.1 & $(2.3-89.5)$ & $<0.001$ \\
\hline Severity during first $12 \mathrm{MB}-\mathrm{MDT}$ intake & & & & & & & & & & & \\
\hline None & $25 / 26$ & 96.2 & $15 / 45$ & 33.3 & & 1.0 & & & 1.0 & & \\
\hline Some & $1 / 26$ & 3.8 & $30 / 45$ & 66.7 & $<0.001$ & 50.0 & $(6.2-405)$ & $<0.001$ & 20.8 & $(2.2-196)$ & 0.001 \\
\hline Severity after first 12 MB-MDT intake & & & & & & & & & & & \\
\hline None & $23 / 24$ & 95.8 & $21 / 39$ & 53.8 & & 1.0 & & & 1.0 & & \\
\hline Some & $1 / 24$ & 4.2 & $18 / 39$ & 46.2 & $<0.001$ & 19.7 & $(2.4-161)$ & $<0.001$ & 4.9 & $(0.5-46.7)$ & 0.121 \\
\hline Severeity before clofazimine intake & & & & & & & & & & & \\
\hline None & $3 / 9$ & 33.3 & $4 / 31$ & 12.9 & & 1.0 & & & & & \\
\hline Some & $6 / 9$ & 66.7 & $27 / 31$ & 87.1 & 0.175 & 3.4 & $(0.6-19.2)$ & 0.170 & & & \\
\hline Severity during clofazimine intake & & & & & & & & & & & \\
\hline None & $8 / 9$ & 88.9 & $12 / 31$ & 38.7 & & 1.0 & & & 1.0 & & \\
\hline Some & $1 / 9$ & 11.1 & $19 / 31$ & 61.3 & 0.010 & 12.7 & $(1.41-14)$ & 0.024 & 9.8 & $(0.9-110)$ & 0.037 \\
\hline
\end{tabular}

lapsing illness is likely to have severe consequences for the patients and their families.

The separation of ENL into acute single, acute multiple, and chronic types emphasizes how few patients experienced a single episode of ENL, and how much more severe and prolonged chronic ENL is when compared with acute ENL. These types could be used in future studies, particularly drug trials, because patients with a chronic profile may need much longer-term immunosuppression than patients with acute multiple disease in which shorter immunosuppression may be adequate. Our figures regarding episodes and drug use illustrate individual patient profile and may be helpful for clinicians in dealing with difficult ENL cases.

This study was conducted when MDT was given to MB cases for 24 months. However, two patients had a duration of ENL that exceeded the 24-month MDT treatment period.
Many countries are now treating MB cases for only 12 months. With a 12 -month duration, $58 \%$ of our cases would have had ENL after completing a 12-month course of MDT. Two important considerations arise from this. First, patients at risk for ENL will lose the protection they receive from the clofazimine component of MB-MDT. Second, it is important to warn patients that their ENL may continue despite their having completed MDT. It is important to advise them to return to the clinic with any new symptoms suggestive of ENL because these might not be recognized as such by health workers inexperienced in leprosy.

Most of our cases had ENL after having started MDT with an overall mean time from diagnosis to the first episode of ENL of 3.2 months. However, some patients had de novo ENL and no apparent previous treatment. We also found a strong association between compliance and the development 
of chronic ENL. This was surprising and there are several possible explanations. MDT kills intracellular mycobacteria, which break up and release antigens. These antigens may then form the focus for the formation of the immune complexes that cause ENL. Regular MDT may result in continued lyses and antigen availability. Alternatively, patients with chronic ENL may be more compliant because they need and seek clinical attention for their ongoing ENL. This possible association between compliance and chronic ENL should be explored further.

Prednisolone was used in our center as the first-line drug for treating moderate and severe ENL. The ENL was managed without prednisolone in only a few patients. The total dosages used per patient were high. Although no overt side effects of chronic prednisolone use were detected, there was no routine screening for adverse effects. Long-term side effects such as hypertension, diabetes, cataract, and osteoporosis could have been undetected in this cohort.

Clofazimine has been shown to be effective in treating ENL and reducing steroid use. ${ }^{13}$ However, it takes 4-6 weeks for the effect of clofazimine to be clinically detectable. Thus, clofazimine is not useful for the management of acute ENL, but may have role in the treatment of chronic ENL. Only $45.5 \%$ of the patients with ENL received clofazimine. The WHO recommends that clofazimine should be given at a dose of 300 $\mathrm{mg} /$ day in divided doses for no longer than 12 months. ${ }^{14}$ In many clinics because of adverse skin and gastrointestinal effects, clofazimine is given at doses of $300 \mathrm{mg} / \mathrm{day}$ for three months, then $200 \mathrm{mg} /$ day for three months, then reduced to $100 \mathrm{mg} /$ day. ${ }^{15}$ Figure 4 shows that when clofazimine was used at a higher sustained dose of 200-300 mg/day the ENL improved but only after several months of treatment at this dose. This improvement may due to clofazimine or a natural resolution of ENL. Some patients with chronic ENL might have benefited from extra clofazimine at these higher doses. However, clofazimine causes marked skin pigmentation that is often unacceptable to our patients in Hyderabad because their peers may recognize that they have leprosy. Short courses of clofazimine at a dose of $100 \mathrm{mg}$ /day have little effect, especially when given early in the course of ENL. Clofazimine is often only available in MDT blister packs. Thus, if it is to be used to ameliorate ENL, loose clofazimine capsules should also be readily obtainable.

We also observed that the last ENL episodes of some patients, especially if MB-MDT was finished, tended to be milder than the earlier ones. This improvement with time has implications for measuring the effectiveness of drugs used in the treatment of ENL.

Thalidomide has been shown in four randomized controlled trials and numerous case series to be very effective in controlling acute ENL and preventing new episodes. ${ }^{10,16}$ Our patients with acute ENL and chronic ENL might have benefited from this drug. Thalidomide was prohibited in India at the time of this study, but it is now available.

This study has highlighted the continuing problem that ENL poses for patients and health care workers even when MDT is routinely used. In 2004, 104,524 new cases of MB were registered in India, of whom $10 \%$ will have a high $\mathrm{BI}$ and be at risk for developing ENL. ${ }^{17}$ Our data suggest that managing patients with prednisolone gives less than adequate control of ENL and that clofazimine is probably not being used optimally. Although there are guidelines suggesting in- creased use of clofazimine in difficult cases, there are no specific guidelines on the most effective way to use clofazimine.

Further prospective clinical studies of ENL are now needed to better define the clinical aspects of the condition and refine response to treatment. Operational studies should be undertaken to optimize the guidelines, defining when and how to use clofazimine and how to monitor its effect.

Received August 10, 2005. Accepted for publication November 22, 2005.

Acknowledgments: We thank BPRC for making their facilities available for this project. The project was initiated and designed by Diana N. J. Lockwood with help from Leonor Pocaterra, Suman Jain, and Sujai Suneetha. Patient data was collected by Suman Jain, Syed Muzaffarullah, and Leonor Pocaterra. Data analysis and write up was done by Leonor Pocaterra and Diana N. J. Lockwood. Diana N. J. Lockwood is the guarantor for this report.

Financial support: The Blue Peter Research Centre and the Dhoolpet Leprosy Research Centre are run and managed by Lepra-India, which is supported by Lepra UK. Additional support is received from the Medical Research Council, UK through Lepra UK. Leonor Pocaterra received a student travel award from the London School of Hygiene and Tropical Medicine student bursary scheme.

Disclosure: Diana N. J. Lockwood was a paid adviser to Pharmion during their application to the European Medicines Agency to have thalidomide licensed for use in the treatment of ENL.

Authors' addresses: Leonor Pocaterra, Clinical Research Unit, London School of Hygiene and Tropical Medicine, London, United Kingdom and Cátedra de Parasitología, Escuela de Medicina JM Vargas, Universidad Central de Venezuela, Caracas, Venezuela. Suman Jain, Rajgopal Reddy, Syed Muzaffarullah, Obdulita Torres, and Sujai Suneetha, Blue Peter Research Centre, Cherlapally, Hyderabad 501 301, AP, India. Diana N. J. Lockwood, Clinical Research Unit, London School of Hygiene and Tropical Medicine, Keppel Street, London WC1E 7HT, United Kingdom, E-mail: diana.lockwood@ Ishtm.ac.uk.

\section{REFERENCES}

1. Bryceson AD, Pfalzgraff RE, 1990. Leprosy. Third edition. Edinburgh: Churchill Livingstone.

2. Wemambu SN, Turk JL, Waters MF, Rees RJ, 1969. Erythema nodosum leprosum: a clinical manifestation of the arthus phenomenon. Lancet 2: 933-935.

3. Sarno EN, Grau GE, Vieira LM, Nery JA, 1991. Serum levels of tumour necrosis factor-alpha and interleukin-1 beta during leprosy reactional states. Clin Exp Immunol 84: 103-108.

4. Waters MF, Rees RJ, Sutherland I, 1967. Chemotherapeutic trials in leprosy. 5. A study of methods used in clinical trials in lepromatous leprosy. Int J Lepr Other Mycobact Dis 35: 311335.

5. Cellona RV, Fajardo TT Jr, Kim DI, Hah YM, Ramasoota T, Sampattavanich S, Carrillo MP, Abalos RM, de la Cruz EC, Ito T, 1990. Joint chemotherapy trials in lepromatous leprosy conducted in Thailand, the Philippines, and Korea. Int J Lepr Other Mycobact Dis 58: 1-11.

6. Nery JA, Vieira LM, de Matos HJ, Gallo ME, Sarno EN, 1998. Reactional states in multibacillary Hansen disease patients during multidrug therapy. Rev Inst Med Trop Sao Paulo 40: 363-370.

7. Schreuder PA, 1998. The occurrence of reactions and impairments in leprosy: experience in the leprosy control program of three provinces in northeastern Thailand, 1987-1995 [correction of 1978-1995]. II. Reactions. Int J Lepr Other Mycobact Dis 66: 159-169.

8. Becx-Bleumink M, Berhe D, 1992. Occurrence of reactions, their diagnosis and management in leprosy patients treated with multidrug therapy; experience in the leprosy control program of the All Africa Leprosy and Rehabilitation Training Center (ALERT) in Ethiopia. Int J Lepr Other Mycobact Dis 60: 173184. 
9. Levy L, Fasal P, Levan NE, Freedman RI, 1973. Treatment of erythema nodosum leprosum with thalidomide. Lancet 2: 324-325.

10. Teo SK, Resztak KE, Scheffler MA, Kook KA, Zeldis JB, Stirling DI, Thomas SD, 2002. Thalidomide in the treatment of leprosy. Microbes Infect 4: 1193-1202.

11. Saunderson P, Gebre S, Byass P, 2000. ENL reactions in the multibacillary cases of the AMFES cohort in central Ethiopia: incidence and risk factors. Lepr Rev 71: 318-324.

12. Chattopadhyay SP, Gupta CM, Bhate RD, Bhate RP, Sreevatsa, 1989. Evaluation of two multidrug regimens in hospitalised multibacillary cases. Indian J Lepr 61: 196-205.
13. Helmy HS, Pearson JM, Waters MF, 1971. Treatment of moderately severe erythema nodosum leprosum with clofazimine-a controlled trial. Lepr Rev 42: 167-177.

14. Expert WHO Committee on Leprosy, 1998. World Health Organ Tech Rep Ser 874: 1-43.

15. Plock H, Leiker DL, 1976. A long term trial with clofazimine in reactive lepromatous leprosy. Lepr Rev 47: 25-34.

16. Lockwood D, Bryceson A, 2003. The return of thalidomide: new uses and renewed concerns-reply. Lepr Rev 74: 290-294.

17. Global leprosy situation, 2005. Wkly Epidemiol Rec 80: 289295. 